\title{
Integrasi pemrograman web pada pemrograman desktop sebagai alternatif fasilitas laporan dalam pengembangan program aplikasi
}

\author{
Mardainis ${ }^{1}$, Khusaeri Andesa ${ }^{2}$ \\ 1,2Program Studi Teknik Informatika, STMIK Amik Riau \\ Jl. Purwodadi Indah Km. 10,5 Panam Pekanbaru, telp 0761-589561 \\ e-mail: ${ }^{1}$ mardainis@stmik-amik-riau.ac.id, ${ }^{2}$ khusaeri@ stmik-amik-riau.ac.id
}

\begin{abstract}
Abstrak
Pemrograman Desktop adalah program aplikasi yang mampu beroperasi tanpa mengandalkan jaringan internet. Penggunaan program desktop biasanya digunakan untuk membuat program yang akan dioperasikan tanpa memerlukan jaringan internet dengan area kerja berada disatu lokasi saja. Sedangkan program web pemakaiannya sangat bergantung pada jaringan internet agar bisa menghubungkan antar pengguna. Pilihan menggunakan program desktop atau program berbasis Web ditentukan oleh kebutuhan dan implementasinya. Jika implementasinya hanya untuk lingkungan perusahaan yang berada di satu tempat, program sebaiknya menggunakan program berbasis desktop. Namun, jika perusahaan memiliki lokasi terpisah di beberapa daerah, penggunaan program berbasis web lebih tepat. Namun banyak programmer, terutama pemula yang enggan menggunakan pemrograman desktop karena dalam membuat laporan harus menggunakan aplikasi pembuat laporan khusus seperti Crystal Report. Kesulitan yang dialami untuk menggunakan aplikasi khusus ini adalah tidak tersedianya aplikasi dalam sistem sehingga perlu diadakan secara khusus. Dalam membuat laporan kadang dirasa agak rumit karena tampilan laporan harus diseting secara manual. Sedangkan dalam bahasa pemrograman berbasis web untuk menampilkan informasi bisa langsung dibuat dengan mudah dalam program itu sendiri tanpa harus menggunakan aplikasi tambahan. Jadi membuat laporan dengan program berbasis web lebih mudah. Untuk menghindari kesulitan para pemrogram dalam membuat laporan tentang program desktop, peneliti mengintegrasikan program berbasis Web dengan pemrograman berbasis desktop dengan tujuan mempermudah membuat laporan.
\end{abstract}

Kata kunci: Pemrograman Desktop, Implementasi, Integrasi, Crystal Report.

\begin{abstract}
Desktop Programming is an application programmer capable of operating without relying on the internet network. The use of desktop programs is usually used to create a program that will be operated without the need for internet network with work area located in one location only. While the web program in use is very dependent on the internet network that can connect between users. The choice of using a desktop program or a Web-based program is determined by its needs and implementation. If the implementation is for a single enterprise environment the program should use a desktop-based program. However, if the company has a separate location in some areas the use of web-based programs is more appropriate. But many programmers, especially beginners who are reluctant to use desktop programming because the report must use a special report maker application such as Crystal Report. The difficulty experienced to use this particular application is the unavailability of apps in the system so it needs to be held specifically. In making the report is sometimes considered a bit complicated because the report view must be manually setup. While in web-based programming language to display information can be directly made easily in the program itself without having to use additional applications. So making reports with web-based programs is easier. To avoid the difficulty of programmers in making reports about desktop programs, researchers integrate Web-based programs with desktop-based programming
\end{abstract}


in order to facilitate reporting Researchers perform desktop-based integration with web-based programming to make reporting easier.

Keywords: Desktop Programming, Implementation,Integration, Web Report.

\section{Pendahuluan}

Untuk membantu pengolahan data yang ada pada instansi pemerintah maupun swasta dibutuhkan beberapa program aplikasi, seperti Sistim Komputer Akuntansi, Sistim Payroll, Sistim Logistik, Sistim Informasi Akademik dan lain lain. Masing masing sistim terhubung dengan beberapa pemakai yang berada dalam suatu instansi baik yang berada dalam suatu kantor maupun di kantor lain. Pembuatan program aplikasi tersebut bisa dibuat dengan menggunakan beberapa pilihan bahasa pemrograman. Yang perlu diperhatikan adalah kebutuhan pemakaiannya, apakah sistim akan digunakan untuk beberapa user yang berada disatu lokasi atau untuk user yang berada dibeberapa lokasi.

Pemrograman Desktop adalah program aplikasi yang mampu beroperasi tanpa mengandalkan jaringan internet. Penggunaan program desktop biasanya digunakan untuk membuat program yang akan dioperasikan tanpa memerlukan jaringan internet dengan area kerja berada disatu lokasi saja. Sedangkan program web pemakaiannya sangat bergantung pada jaringan internet agar bisa menghubungkan antar pengguna yang berada dibeberapa lokasi yang berbeda. Pilihan menggunakan program desktop atau program berbasis Web ditentukan oleh kebutuhan dan implementasinya. Jika implementasinya hanya untuk lingkungan perusahaan yang berada di satu tempat, program sebaiknya menggunakan program berbasis desktop. Namun, jika perusahaan memiliki lokasi terpisah di beberapa daerah, penggunaan program berbasis web lebih tepat. Namun banyak mahasiswa maupun programmer, terutama pemula yang enggan menggunakan pemrograman desktop karena dalam membuat laporan harus menggunakan aplikasi pembuat laporan khusus seperti Crystal Report. Kesulitan yang dialami untuk menggunakan aplikasi khusus ini adalah tidak tersedianya aplikasi tersebut dalam sistem sehingga perlu diadakan secara khusus. Dalam pemakaiannya terlebih dahulu harus dilakukan konfigurasi dan instalasi. Kadang kala proses konfigurasi dan instalasi ini mengalami kendala dipengaruhi oleh spesifikasi sistim operasi dan komputer terutama untuk pemakaian multi user. Pembuatan format laporan yang komplit dilakukan dengan cara manual sehingga membutuhkan waktu lebih lama. Pembuatan laporan dengan menggunakan Crystal Report ini pernah dibahas oleh Budi Pramana, S.Kom dalam Ilmu Komputer.com dengan topic "Laporan Menggunakan Crystal Report Pada Visual Basic 2010". Pembuatan laporan dilakukan dengan mengikuti beberapa tahap.

Sedangkan dalam bahasa pemrograman berbasis web untuk menampilkan informasi bisa langsung dibuat dengan mudah dalam program itu sendiri tanpa harus menggunakan aplikasi tambahan. Pembuatan laporan berbasis web pernah dibahas oleh Yudi Utama dalam jurnalnya dengan judul "Sistem Informasi Berbasis Web Jurusan Sistem Informasi Fakultas Ilmu Komputer Universitas Sriwijaya". Langkah langkah pembuatan laporannya terlihat lebih mudah dan simple.

Penelitian ini akan membahas bagai mana membuat laporan pada program web namun dapat dipanggil melalui program desktop. Untuk menghindari kesulitan para pemrogram dalam membuat laporan tentang program desktop, peneliti mengintegrasikan program berbasis Web dengan pemrograman berbasis desktop dengan tujuan mempermudah membuat laporan. Pemrograman web difokuskan untuk menampilkan hasil pengolahan data yang akan ditampilkan menjadi informasi atau laporan-laporan yang digunakan dalam aplikasi. 


\section{Rumusan Masalah}

Dari latar belakang masalah diatas dapat dirumuskan masalah sebagai berikut :

1. Pada bahasa pemrograman yang berbasis desktop harus menggunakan aplikasi tambahan untuk menampilkan informasi dari hasil pengolahan data serta banyak kendala untuk instalasi dan konfigurasi terutama pada aplikasi multi user.

2. Pada aplikasi tambahan, untuk membuat format laporan dengan tampilan dan proses yang beragam terasa lebih rumit karena diseting manual.

3. Pembuatan laporan dalam pemrograman web lebih mudah.

\section{Batasan Masalah}

Dalam penelitian ini dibatasi masalah sebagai berikut :

1. Penelitian ini menfokuskan pada pengolahan data dari database menjadi informasi menggunakan bahasa pemrograman berbasis web yang bisa di integrasikan pada bahasa pemrograman berbasis desktop.

2. Database yang digunakan adalah database mysql dan bahasa pemrograman desktop yang digunakan Visual Basic sedangkan bahasa pemrograman berbasis web menggunakan PHP.

\section{Tujuan Penelitian}

Adapun tujuan dari penelitian ini adalah : Mengintegrasikan bahasa pemrograman berbasis web pada bahasa pemrograman berbasis desktop sebagai alternatif pembuatan laporan yang lebih efesien dan efektif serta fleksibel.

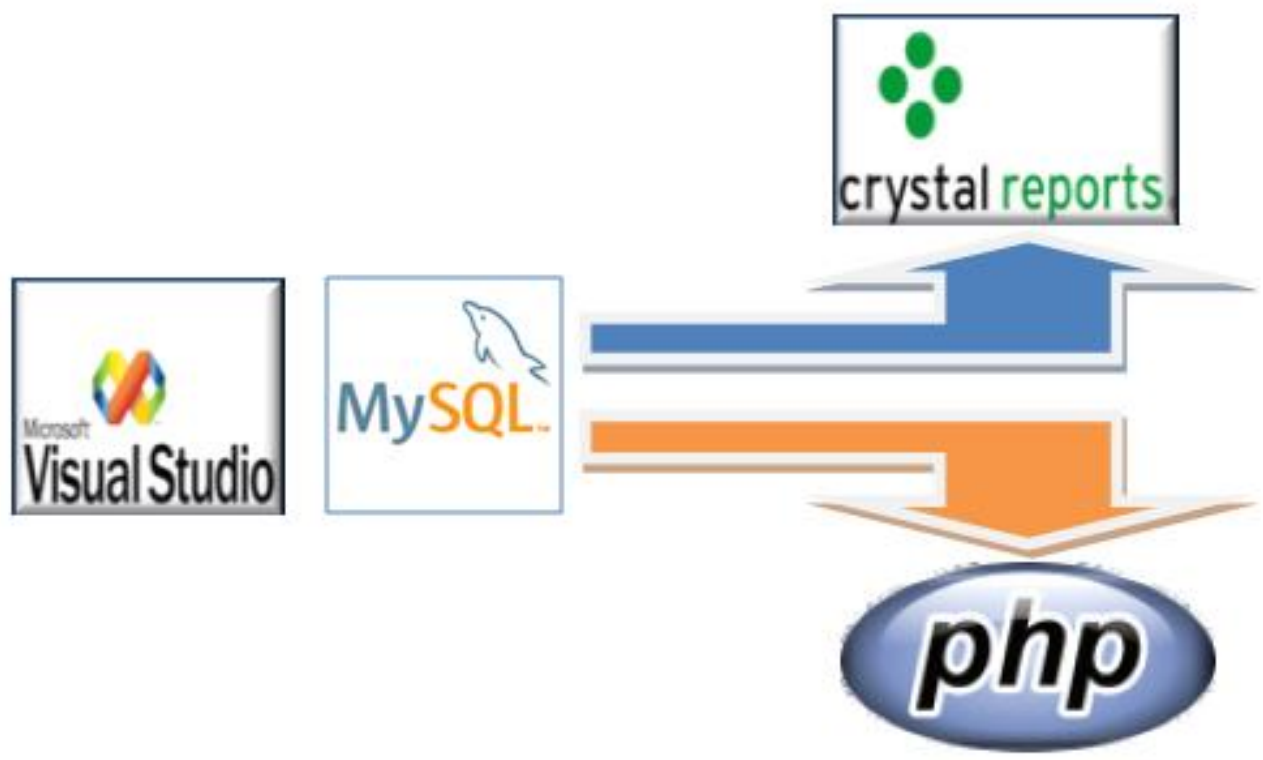

Gambar 1. Model Itegrasi Program 
Skema yang ditampilkan gambar 1. Diatas memperlihatkan konsep pemrograman yang menggunakan bahasa pemrograman desktop. Bahasa pemrogragaman desktop yang populer digunakan adalah Microsoft Visual Basic Data disimpan dalam database MySql selanjutnya laporan dibuat menggunakan software khusus seperti crystal report. Penelitian ini membuat alternatif lain dalam membuat laporan dengan menggunakan bahasa pemrograman web PHP.

\section{Metode Penelitian}

Sebagai bahan kajian dalam penelitian ini dilakukan rujukan kebeberapa hasil penelitian yang sudah dilakukan beberapa peneliti sebelumnya yang berguna sebagai pedoman, pembanding dari penelitian ini. Beberapa hasil penelitian rujukan adalah sebagai berikut :

Deffri Ananta menjelaskan dalam jurnalnya, pengertian dari system adalah sekumpulan elemen yang berhubungan satu dengan yang lain secara fungsional. Agar suatu system terlaksana diperlukan data yang relavan, akurat, tepat guna dan tepat waktu yang memungkinkan pihak manajemen pihak manajemen dapat mengambil suatu keputusan yang tepat[1]

Menurut Dadi Rosadi dalam penelitiannya "Web adalah ruang informasi dalam internet, dengan menggunakan teknologi hyperteks, pemakai dituntun untuk menemukan informasi dengan mengikuti link yang disediakan dalam dokumen web yang ditampilkan dalam browser web." [2]

Aplikasi web merupakan perangkat lunak yang dijalankan melalui web browser, sehingga dapat diakses melalui perangkat desktop ataupun mobile. Aplikasi web adalah sebuah sistem informasi yang mendukung interaksi pengguna melalui antarmuka berbasis web dan bagian dari client-side yang dapat dijalankan oleh web browser.[3]

Pemrograman Visual Berbasis Desktop adalah pemrograman yang di lakukan dengan memanipulasi elemen-elemen visual yang di lakukan pada sebuah PC tunggal yang pengoperasiannya tidak bergantung pada PC lain dalam jaringan maupun web.[4]

D. S. U. Mardianto dalam penelitiannya menjelaskan "Crystal Reports merupakan salah satu program yang digunakan untuk membuat, menganalisa, dan menterjemahkan informasi yang terkandung dalam data- base ke dalam sebuah laporan. Crystal Reports dirancang untuk membuat laporan yang dapat digunakan dengan berbagai bahasa pemrograman berbasis Windows, seperti Visual Basic, Visual $\mathrm{C} / \mathrm{C}++$, Visual Interdev, dan Borland Delphi.’[5]

Budi Permana dalam e-booknya menjelaskan "Crsytal Report adalah sebuah komponen control pada toolbox yang digunakan untuk membuat laporan dari berbagai sumber data. Sumber data disini bisa dikatakan database, dengan menggunakan Crystal Report kita dapat membuat laporan yang datanya diperoleh dari Database apapun, misalnya SQLServer, Ms. Access, Mysql, dll. Crystal report pada visual basic 2010 tidak langsung disertakan pada saat kita menginstal visual studio, jadi mau tidak mau kita harus menginstal crystal report secarah terpisah. Untuk mendapatkan Crystal Report anda bisa mendapatkanya melalui search engine google dengan kata kuncin SAP Crystal Report for Visual Basic 2010”.[6]

Syaifudin Ramadhani menulis dalam penelitiaSyaifudin Ramadhani,nnya "MySQL adalah sebuah perangkat lunak sistem manajemen basis data SQL (bahasa Inggris: database management system) atau DBMS yang multithread, multi-user, dengan sekitar 6 juta instalasi di seluruh dunia. MySQL AB membuat MySQL tersedia sebagai perangkat lunak gratis dibawah lisensi GNU General Public License (GPL), tetapi mereka juga menjual dibawah lisensi komersial untuk kasus-kasus dimana penggunaannya tidak cocok dengan penggunaan GPL. Relational Database Management System (RDBMS)".[7]

XAMPP merupakan paket PHP dan MySql berbasis open source yang dapat digunakan sebagai tool pembantu pengembangan aplikasi berbasis PHP. XAMPP mengombinasikan beberapa paket 
perangkat lunak berbeda ke dalam satu paket. Sampai XAMPP versi 1.7.3 beberapa paket dibundel adalah sebagai berikut Apache HTTPD, mod_autoindex_color module. FileZilla FTP Server dan lain lain.[8]

Untuk memudahkan dalam membuat database, tabel dan record record dilakukan terlebih dahulu XAMPP harus diinstall terlebih dahulu. Jika XAMPP sudah diinstall maka PHP, MySql dan Apache secara otomatis terinstall.[9]

Penelitian ini bertujuan untuk Mengintegrasikan bahasa pemograman berbasis web pada bahasa pemograman berbasis desktop sebagai alternatif fasilitas report yang lebih efesien dan efektif serta fleksibel.Berdasarkan tujuan tersebut, maka penelitian ini termasuk penelitian eksploratif (explorative research). Eksplanatori adalah penelitian yang bertujuan menganalisis hubungan-hubungan antara satu variabel dengan variabel lainnya atau bagaimana suatu variabel mempengaruhi variabel lainnya.[10] Dasar dari pemilihan rancangan penelitian tersebut adalah:

1. Mengidentifikasi kebutuhan hardware dan software untuk pemograman desktop merupakan suatu kajian menentukan standar yang digunakan oleh programer untuk membuat suatu aplikasi yang menggunakan basis pemograman desktop.

2. Mengidentifikasi kebutuhan hardware dan software untuk pemograman web dalam hal ini dilakukan kajian tentang kesesuaian spesiifikasi yang digunakan dengan pemograman desktop yang akan diintegrasikan.

3. Mengidentifikasi dan memformulasikan teori, dan syntax pemograman untuk laporan master dan detail yang mencakup pada kebutuhan laporan yang sering digunakan oleh programer.

Langkah langkan dari penelitian dapat dilihat pada Fish Bond berikut :

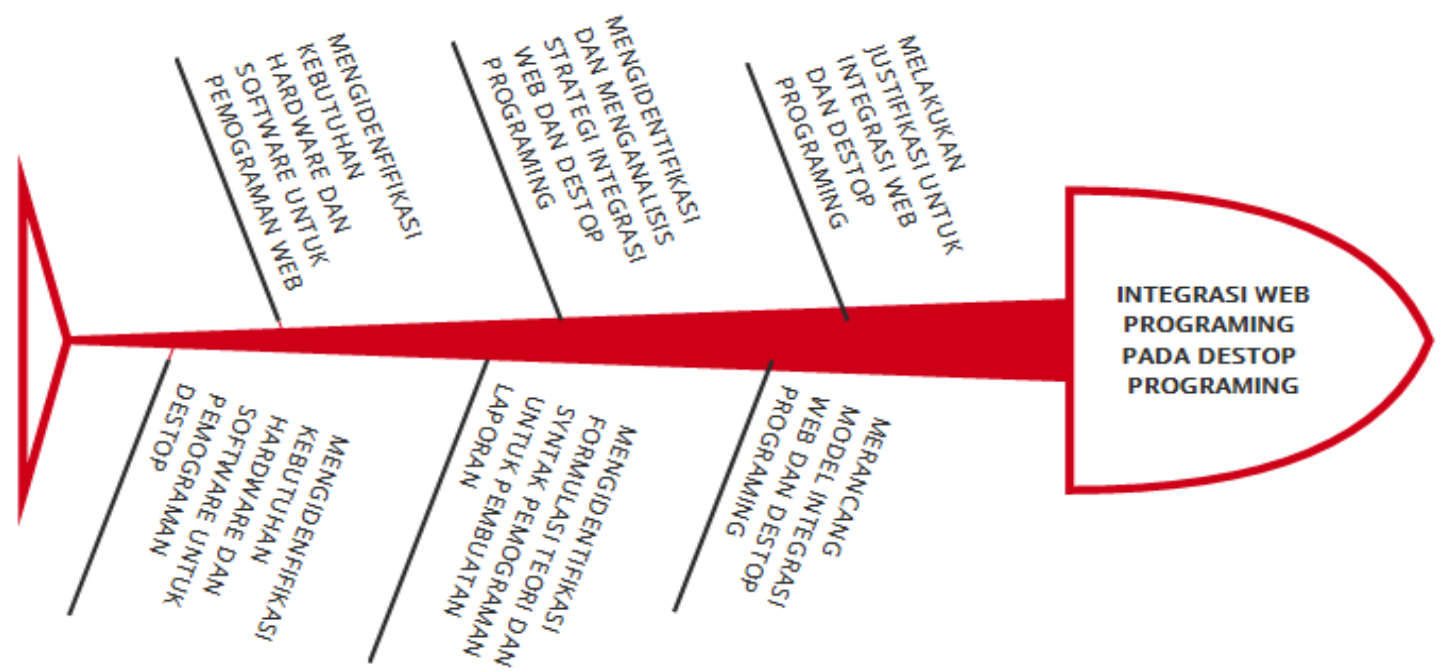

Gambar 2. Fishbond penelitian

Tahapan Penelitian

Bedasarkan rancangan penelitian diatas dilakukan tahapan penelitian yang direncanakan dalam 1 tahun dengan langkah sebagai berikut :

1. Mengidentifiksi kebutuhan Hardware dan software untuk pengunaaan bahasa pemograman desktop yang mendukung programer untuk mengimplementasikan rancangan dan ujicoba program yang telah berhasil dibuat. 
Kebutuhan hardware dalam penelitian ini minimal membutuhkan 1 unit Laptop dengan spesifikasi minimal core to duo dengan sistim operasi minimal microsoft windows 7 dan bahasa pemrograman microsoft visual basic 6 serta crystal report 8 .

2. Mengidentifikasi kebutuhan hardware dan software untuk penggunaan bahasa pemograman web yang mendukung pembuatan laporan-laporan program yang sering digunakan oleh programer dalam implementasi rancangan dan ujicoba program.

3. Kebutuhan hardware dalam penelitian ini minimal membutuhkan 1 unit Laptop dengan spesifikasi minimal core to duo dengan sistim operasi minimal microsoft windows 7 serta bahasa pemrograman PHP dengan tek editor macromedia dreamweaver 8 dan Exam.

4. Mengidentifikasi dan memformulasikan teori, dan syntax pemograman yang digunakan oleh programer untuk implementasi laporan-laporan program yang sesuai kebutuhan programer.

Pada tahap ini dibahas cara pembuatan laporan dengan crystal report dan dengan menggunakan PHP.

5. Mengidentifikasi dan menganalisis strategi integrasi pemograman web pada pemograman desktop yang digunakan untuk laporan-laporan program. Pada tahap ini dilakukan penggabungan program PHP dengan pemrograman desktop. Penggabungan PHP dengan program desktop dilakukan dengan memanfaatkan fasilitas tool webrowser di program desktop.

6. Merancang model-model integrasi laporan yang dibuat pada web dengan pemograman desktop utuk dapat dijadikan standar yang digumakan oleh programer.

7. Melakukan justifikasi expert untuk strategi integrasi pemograman web pada pemograman desktop yang dapat digunakan sebagai salah satu alternatif pembuatan laporan program yang dinamis dan fleksibel.

Metodologi Penelitian disusun beberapa tahap sebagai berikut

1. Waktu dan Tempat Penelitian

Lamanya waktu pelaksanaan penelitian adalah selama 6 bulan yaitu pada bulan Aptil 2017 sampai Oktober 2017, penelitian dilaksanakan di kampus STMIK Amik Riau Pekanbaru.

2. Teknik Pengumpulan Data

Pengumpulan data dilakukan dengan menggunakan beberapa teknik berikut

a. Pengamatan (observasi).

Pengamatan dilakukan dengan melihat secara langsung proses pembuatan program aplikasi oleh beberapa mahasiswa dan programmer.

b. Wawancara (interview)

Wawancara dengan cara tanya jawab langsung dengan mahasiswa dan programmer dalam pembuatan program. Pertanyaan utama yang ditanyakan adalah mana yang lebih diminati pemrogram desktop atau pemrograman web dalam membangun sebuah sistim.

c. Penelitian Kepustakaan

Pada tahap ini penulis mencari bahan referensi terkait dengan topic penelitian, dengan cara membaca buku buku ataupun browsing diinternet untuk mencari artikel maupun jurnal yang terkait dengan penelitian penulis.

3. Metode Pengembangan

Metode pengembangan digunakan untuk merancang pembuatan laporan lebih mudah dalam pemrograman desktop.

a. Rancangan Penelitian

Rancangan penelitian berisikan pengetahuan, algoritma, metode, produk(sistem) atau model untuk menunjang penelitian. Objek serta variabel yang di teliti adalah 
cara membuat laporan berbasis web untuk dapat diintegrasikan dengan program berbasis desktop.

b. Pemrograman.

Pengolahan dimaksudkan disini adalah membuat program aplikasi sebagai simulasi pembuatan laporan baik dengan menggunakan crystal report maupun dengan program web. Selanjutnya dilakukan analisa data untuk melihat kemudahan yang diperoleh setelah dilakukan integrasi program web ke program desktop khusus dalam membuat laporan.

c. Pengujian

Pengujian dilakukan untuk melihat apakah laporan yang dihasilkan program web bias terintegrasi ke program desktop.

\section{Hasil dan Pembahasan}

Hasil dari pembahasan dalam penelitian ini diperoleh langkah langkah pembuatan laporan dari sistim baik menggunakan metode desktop maupun metode web.

Bentuk form input data yang dibuat dengan bahasa pemrograman microsoft visual basic, datanya disimpan dalam database mysql.

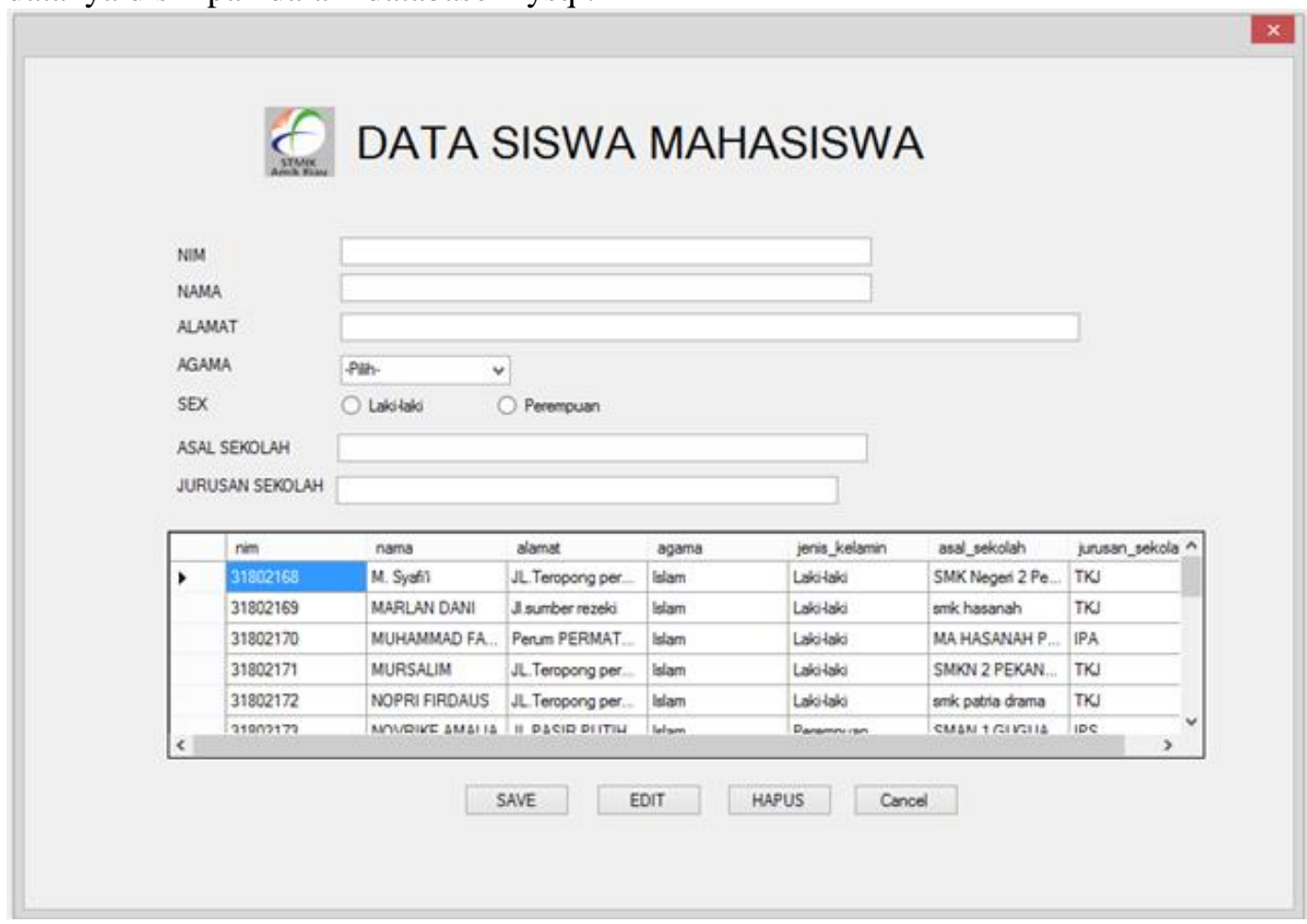

Gambar 3. Tampilan form input data yang dibuat dengan microsoft visual basic.

Data yang diinputkan tersebut akan disimpan dalam database mysql. Selanjutnya untuk menampilkan laporan dilakukan dengan 2 cara, yakni menggunakan crystal report dan php, dengan maksud untuk memperlihatkan perbandingan diantara kedua software tersebut.

Berikut adalah langkah-langkah pembuatan Laporan dengan Crystal Report dalam pemrograman desktop

1. Buat Form Baru

2. Pilih CrytalReportViewer

3. Klik kanan pada name project $>$ Add $>$ New Item 
4. Categories $>$ Reporting $>$ CrystalReport

5. Choose an Expert $>$ Standard

6. Available Data Sources $>$ Create New Connection

7. Pilih data source yang telah dibuat

8. Klik Next $>$ Finish

9. Klik nama tabel 2 kali

10. Klik Database Fields

11. Klik nama tabel

12. Tarik field-field ke dalam section3

13. Untuk melihat hasil sementara klik Main Report Preview

14. Kembali ke fom 1

15. Klik form > Properties $>$ ReportSource> pilih nama CrystalReport

16. Jalankan Program

Dari langkah langkah tersebut diatas dapat diketahui bahwa untuk membuat laporan dibutuhkan 16 langkah untuk dapat menghasilkan laporan seperti disajikan pada gambar 4 berikut :

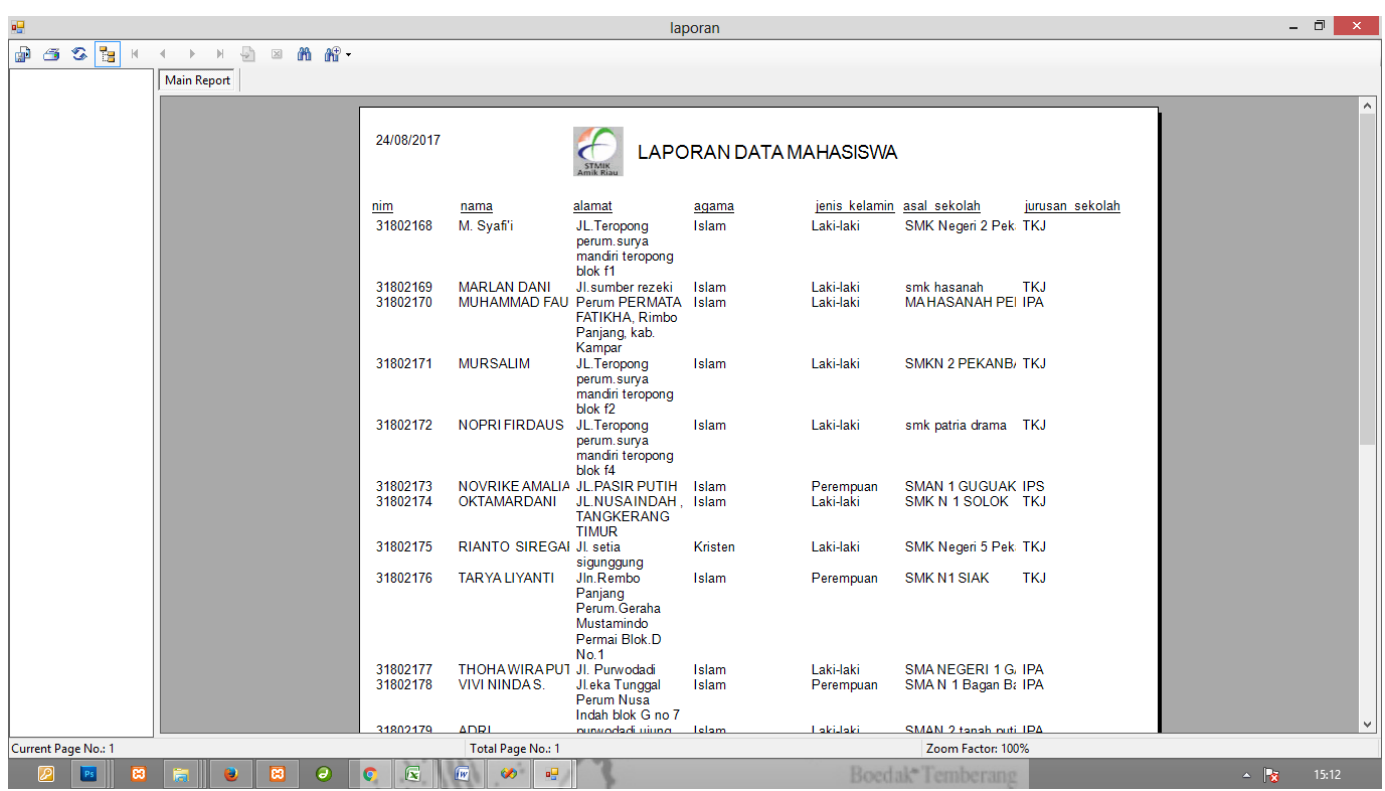

Gambar 4. Laporan informasi data mahasiswa menggunakan crystal report.

Sementara langkah-langkah membuat laporan dengan menggunakan bahasa pemrograman web PHP jauh lebih sederhana sebagai berikut :

1. Siapkan Form baru pada program Visual Basic

2. Klik pilihan tools Webrowser 


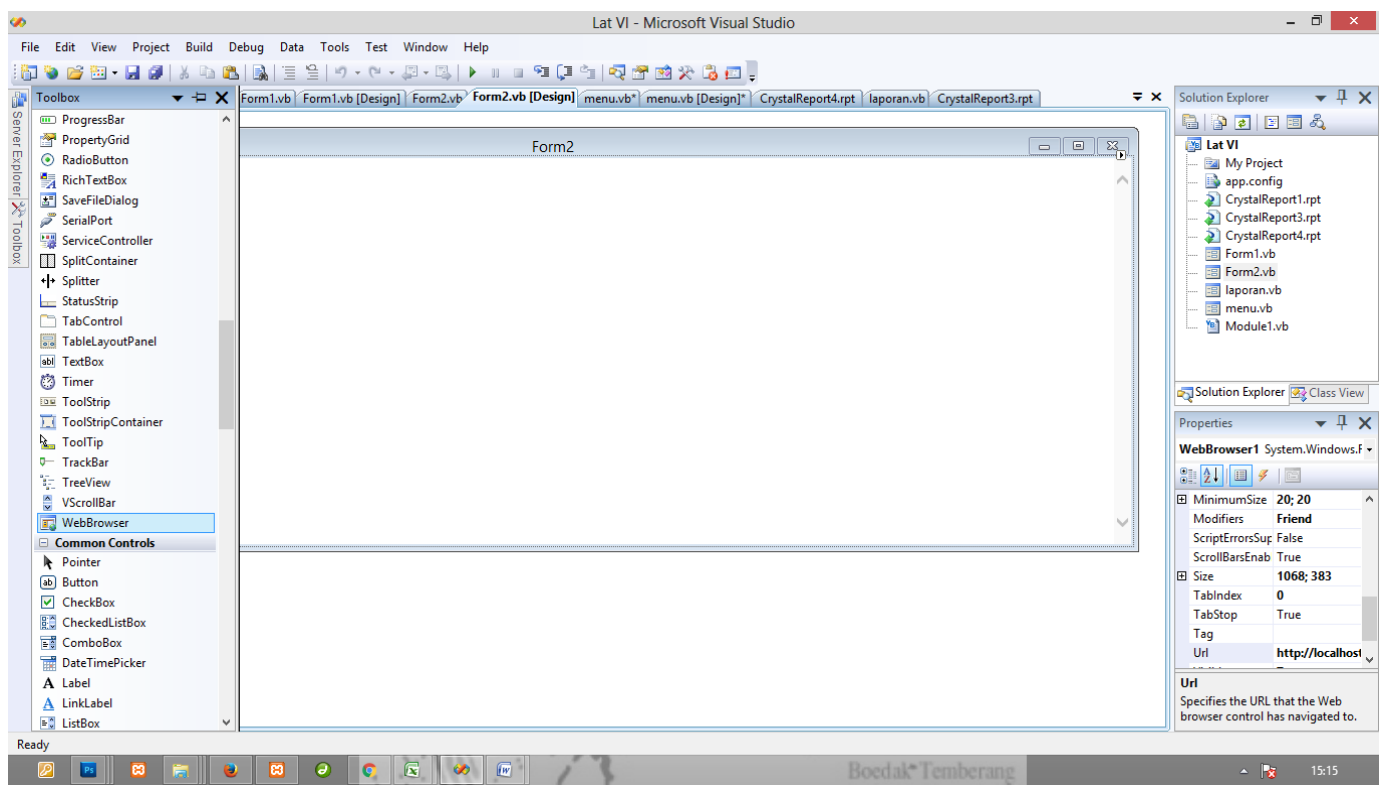

Gambar 5. Pilihan tool untuk membuat laporan dengan php.

Agar laporan yang dibuat dengan php bisa dipanggil dari pemrograman microsoft visual basic, maka pada program kita siapkan tool yang akan digunakan sebagai pemanggil, yaitu webbrowser seperti ditampilkan pada gambar 5 .

- $\quad$ Ketikkan skrip program seperti yang tercantum dibawah

Public Class Form2

Private Sub Form2_Load(ByVal sender As System.Object, ByVal e As System.EventArgs) End Sub

Handles MyBase.Load WebBrowser1.Navigate("http://localhost/mhs/index.php")

Private Sub WebBrowser1_DocumentCompleted(ByVal sender As System.Object, ByVal e As System.Windows.Forms.WebBrowserDocumentCompletedEventArgs) Handles End Sub

WebBrowser1.DocumentCompleted

End Class

- Ketika program dijalankan maka hasilnya seperti ditampilkan dibawah

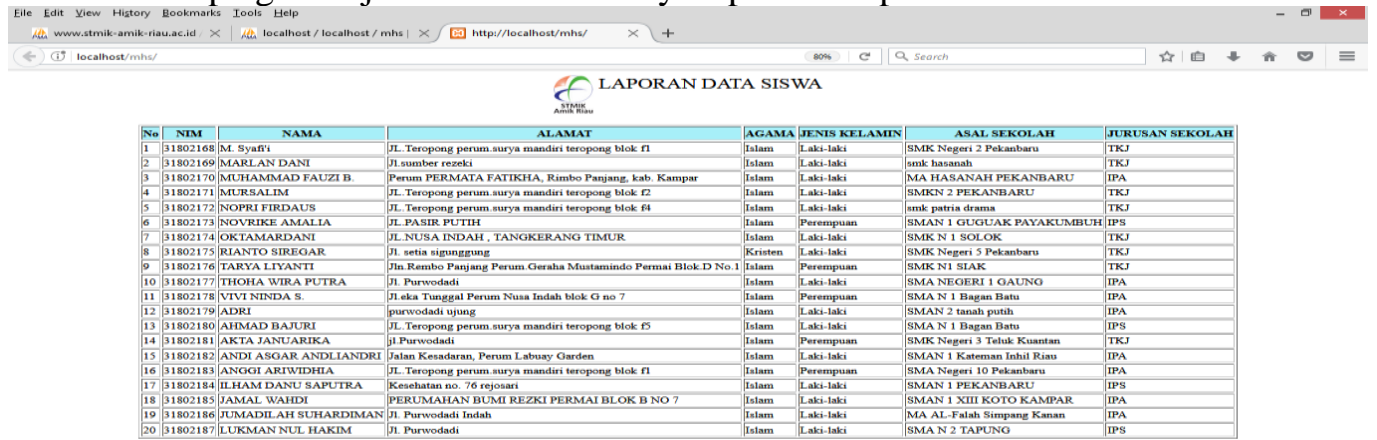

Gambar 6. Laporan informasi data mahasiswa menggunakan php. 
Selanjutnya dari masing masing laporan dapat dihubungkan ke dalam pemrograman desktop untuk dapat di panggil melalui menu program.

\section{Kesimpulan}

Kesimpulan dari hasil penelitian ini disimpulkan bahwa pembuatan laporan dengan menggunakan bahasa pemrograman web bisa diintegrasikan dengan pemrograman desktop. Hal ini bisa dijadikan sebagai solusi bagi programer untuk membuat laporan apabila software crystal report tidak tersedia, khususnya untuk program berbasis desktop. Pembuatan laporan bisa lebih sederhana tanpa perlu melakukan seting yang rumit seperti yang dilakukan dalam pembuatan laporan di crystal report. Pengujian dilakukan untuk membuat laporan yang sederhana dengan menggunakan crystal report dan bahasa pemrograman web PHP. Disimpulkan bahwasanya pembuatan laporan dengan menggunakan bahasa pemrograman web PHP lebih mudah.

\section{Daftar Pustaka}

[1] S. M. P. N. Sungailiat, s. Informasi, s. Atma, and 1. Pangkalpinang, "berbasis aplikasi desktop pada."

[2] j. Computech, d. Rosadi, and u. Lousiani, "aplikasi pembuatan laporan keuangan," vol. 6, no. 2, pp. 96-100, 2012.

[3] a. T. Pangkerego and s. R. Pungus, "perancangan aplikasi laporan kegiatan berbasis web pada bpjn xi satker wilayah ii sulawesi utara," pp. 6-7, 2016.

[4] i. Bagi, s. Smk, n. Surakarta, d. Asm, and j. Pendidikan, "peningkatan aktifitas belajar pemrograman visual berbasis desktop melalui pemanfaatan alat peraga progam aplikasi inventaris bagi siswa smk negeri 5 surakarta basori 1 , dona asm'ul khusnawan 2," pp. $6-15$.

[5] b. Data, "rancang bangun aplikasi toko menggunakan visual basic 9 .0 ' studi kasus roberta superstore,"” pp. 1-7, 2005.

[6] b. Permana and s. Kom, "l a p o r a n m e n g u n a k a c ry st a l reportpad a vi s u a 1 b a s i c 2010 ," pp. 1-7, 2007.

[7] s. Ramadhani, u. Anis, and s. T. Masruro, "rancang bangun sistem informasi geografis layanan kesehatan di kecamatan lamongan dengan php mysql," vol. 5, no. 2, pp. 479484, 2013.

[8] riyanto, membuat aplikasi mini market integrasi barcode reader dengan php \& mysql. Penerbit gava media, 2014.

[9] i. Y. Supardi, study, semua bisa menjadi programmer visual basic 2010 case. Elek media koputindo, 2013.

[10] b. A. Perkuliahan, "metodologi penelitian," 2010. 